\title{
Depositional environments of Neoarchean carbonates from the Dharwar Craton, India: Constraints from Geochemical and Isotopic studies
}

\author{
A.V. GOVIND ${ }^{1}$, K. BEHERA ${ }^{1}$,
}

S. BALAKRISHNAN ${ }^{1}$ J.K. DASH ${ }^{1}$ R. BHUTANI ${ }^{1}$, S. MANAGAVE $^{2}$, R. SRINIVASAN ${ }^{3}$

${ }^{1}$ Department of Earth Sciences, Pondicherry University Puducherry, 605014 (vipinaoh1@gmail.com)

${ }^{2}$ Earth and climate science, IISER Pune, Pune 411008, India

${ }^{3}$ Centre for Atmospheric and Ocean Sciences, Indian Institute of Science, Bangalore- 560012

Carbonate rocks are a minor yet relevant component of Archean Dharwar craton. Exposures of Neoarchean carbonates $(\sim 2.7 \mathrm{Ga})$ serve as a valuable proxy to study the past ocean-atmospheric conditions. Samples from different parts of Vanivilas Formation, mostly dolomitic limestones and cherty dolomites with mica, graphite associations were studied.

Most samples showed a substantial level of preservation of geochemical proxies. Depleted LREEsn and slightly enriched HREESN patterns, superchondritic Y/Ho values, La, Eu and Y anomalies and lack of Ce anomaly in most of the samples indicated preservation of marine signatures. Presence of positive Eu anomaly in all the samples indicates the influence of hydrothermal fluids in Neoarchean oceans. The $\mathrm{C}$ isotopic compositions of most samples fall in the range of $0 \pm 0.5 \%$, with few samples show deviation in primary composition due to metamorphic decarbonation. Considerable depletion in $\delta^{18} \mathrm{O}$ values are observed and can be attributed to later interactions with fluids. The ${ }^{87} \mathrm{Sr}^{86} \mathrm{Sr}_{i}$ ratios of most of the samples are close to the estimated $\mathrm{Sr}$ isotopic composition of 2.7 Ga oceans, however, in some places, radiogenic values are encountered owing to post-depositional alterations.

Variable $\varepsilon_{\mathrm{Nd}}(-8.39$ to +5.83$)$ values indicate input from a pre-existing continental crust and markedly depleted mantle sources, with highly radiogenic $\boldsymbol{\varepsilon}_{\mathrm{Nd}}$ suggesting mantle heterogeneity in the region. Samples associated with Fe-Mn deposits are characterised by higher $\mathrm{Y} / \mathrm{Ho}, \mathrm{La}, \mathrm{Eu}$ anomalies, much-depleted LREEs and +ve $\varepsilon_{\mathrm{Nd}}$ values suggesting deeper depositional sites thus better preserving the hydrogenous character. Samples including those with stromatolitic structures show lower Y/Ho, La, Eu anomalies, less depleted LREEs and -ve $\varepsilon_{\mathrm{Nd}}$ values suggesting deposition in a shallow marine environment where seawater composition was also influenced by continental input. 
This abstract is too long to be accepted for publication.

Please revise it so that it fits into the column on one page. 